\title{
Evaluation of urban space in the context of environmental psychology and safety
}

\author{
Malgorzata Gerus-Gosciewska \\ University of Warmia and Mazury in Olsztyn, Faculty of Geodesy and Land Management, Department of Cadastre and Spatial Management \\ ul. Prawochenskiego 15, 10-724 Olsztyn, Poland
}

\begin{abstract}
The city as a complex organism has the task of ensuring safety to people besides fulfilling their physical and social needs. In creating space around us, we use its resources and values for our own use, to form the best existence possible. Taking into consideration the assumptions of environmental psychology that there is a feedback relationship between man and the environment, we can assume that in shaping a safe space, we shape our safety. The aim of the paper is an evaluation of urbanized geospace features, in the context of safety using environmental psychology. The effect of space components on safety was obtained from the results of a questionnaire survey to identify the importance of specific features. The results were standardized by quotient transformation relative to a reference point, where the maximum value was adopted as the reference point. The evaluation was carried out in the context of the intensity of the presence of individual geospatial features in urban space and the evaluation result is a safety risk map. The evaluation results can be used to determine rules which can contribute to the solution of practical problems related to the shaping of safe urban space.
\end{abstract}

Keywords: physical planning; characteristics of space; safe urban space; environmental psychology.

\section{Introduction}

Environmental psychology deals with social problems related to the physical human living environment. Every person always performs his or her living activities in some environment, which, depending on its form, has a positive or negative effect on aspirations, living functions and behavior. When the space is empty, devastated or taken over by undesired persons, this basically means serious errors in the design or in management, or in both of these aspects [1].

When cities and estates ensure safe spaces, the residents have a strong feeling of safety and, conversely, when these goals are absent, the residents may feel endangered in space. Residents have a broad view and valuable insights into how the area in which they move every day functions and they know from experience which parts are dangerous and why.

The basic task of environmental psychology is to focus on everyday reality, i.e. meeting social needs and expectations [1]. The subject of the study are problems occurring at the meeting point of human spatial needs and expectations towards this space in the context of a safe life. The research area focuses on the relationship between an individual and the safety of his or her environment.

\section{Outline of spatial perception theory}

Environmental psychology, which was created around 40 years ago, deals with man in his general environment. It examines environment-man relations concerning the problem of how to shape the environment to make it human-friendly, which is connected with problems in shaping environment-friendly human behavior, solving social dilemmas or shaping environmental awareness in people [2].

"Perception" is a term taken from psychology, from studies of imagery used in a changed meaning. Perception is treated here rather as a certain social process, mediating the relations between man and the environment. As Ittelson states, "in the field of environmental psychology, the term perception was developed into the broader expression environmental perception, which includes cognition more generally (with perception, thinking, imagery, etc. as subtopics) as well as affect, meaning and valuation" [3].

Corresponding author: Malgorzata Gerus-Gosciewska. E-mail address: chagos@uwm.edu.pl http://dx.doi.org/10.3846/enviro.2014.118

(C) 2014 The Author. Published by VGTU Press. This is an open-access article distributed under the terms of the Creative Commons Attribution License, which permits unrestricted use, distribution, and reproduction in any medium, provided the original author and source are credited. 
The problems of environment perception aroused the greatest interest in the 1960s and 70s, in such sciences as: psychology, sociology, anthropology, urban planning, spatial planning [4]. Psychology, sociology, ethology, architecture, geography and spatial planning, among others, deal with the problems of environment perception and jointly create a new field of study. Psychology comes first, not by chance, because its contribution to the development of this new scientific discipline is the greatest [3].

Theories of perception were used by Cymerman et al. in adaptation of Wejchert's impression curve method for rural landscape assessment [5]. Bajerowski's method also uses space imagery in landscape valuation [6].

In spatial planning, studies of imagery involve the use of the results of questionnaire surveys conducted among local communities in programming the development of given communes [7, 8]. In spatial planning theory, environmental perception was used in the questionnaire survey to evaluate the benefits of the neighborhood of planning functions [9].

Modern environmental psychology, apart from inner relations and transformations occurring in people, also deals with the human physical environment. This environment is understood as all information received by a person and organizing human behavior [1].

\section{Environmental psychology in spatial design}

As a result of the economic transformations of the 1990s and the large scale of investment projects, the user has been completely deprived of influence on the shape of his or her living space. Architects and urban planners, convinced that they are acting for the good of the individual and society, spoke about people's low awareness regarding their real needs when they met with criticism and dissatisfaction. The architects started to design, not for a particular individual investor, but for anonymous users. The actions of architects and urban planners thus got out of social control, which was soon replaced by bureaucratic control (standards, laws etc.).

It cannot be said that "projects" are not good for a community - because they can be. But projects are usually carried out for political reasons or for the needs of business or developers. A project is extremely rarely the effect of a social discussion, concerning the creation of good spaces for the local community. The vision developed by the local community in most cases is very realistic and practical, but also includes innovative ideas because it is much broader than what a single expert or agency can propose. [10]

The categories of objective functionality work best in the planning process. Studying people's manner of spatial perception may become one of the factors influencing planning solutions because it is they who are to live in the programmed spaces [3].

The shape of the natural environment, along with the social environment, should satisfy the residents' needs and these are often perceived by planners from their own perspective, without sufficient identification of the subjective feelings of those who live in the designed environments. Space has a public character, but the manner of spatial shaping and use cannot be solely the domain of the urban planner, but an educated spatial manager, who will take into account the community's wishes at the time of spatial plan creation.

The above problems were regulated by the Spatial Planning and Land Development Act of 2003. According to the provision (Art. 18.1 of the Act), objections to the draft local plan can be raised by anyone who disputes the decisions adopted in the draft plan. Society's rights concerning participation in the draft local plan are also set forth in Art. 17.11 and in the draft study of a commune's land use conditions and directions in Arts. 11.10 and 11.11 [11]. The planning process requires consultation with the community at the beginning. This approach assumes that professionals extract ideas arising from the community - they track its point of view and real problems, but even more importantly, local ideas for changes in local public spaces. The role of professionals is then to implement the vision created by the local community [10].

For the draft study, active participation of the commune's residents in matters important for the commune, its residents or particular social groups consists in getting them involved in document creation, making key decisions and solving local problems. This is statutorily guaranteed by public discussion on the solutions adopted in this draft study. The law guarantees social participation of the residents with communal authorities and their mutual cooperation.

In every psychological activity, the environment is an active moderator of social processes and for a planner it can become the inherent context of practical action [1].

In creating space around us, we try to form the best possible conditions for a safe life, using its resources and values.

\section{Isolation of spatial features affecting spatial safety by brainstorming}

When people describe their favorite place with such words as "safe", "interesting" and "attractive", this means that they are ready to return there. This type of term describes difficult-to-explain, immeasurable features - the qualitative aspects - of a particular space [10].

Brainstorming among students in the field of land management of UWM in Olsztyn was used in the paper to isolate the spatial features affecting urban space safety. The students evaluated the spatial entourage of the city of Olsztyn to isolate features which affect spatial safety. The results highlighted the list of features with a negative effect on spatial safety (Table 1). 
Table 1. Spatial features with a negative effect on urban spatial safety

\begin{tabular}{ll}
\hline Feature number & Feature name \\
\hline 1 & Unlit streets \\
2 & Club, pub, all-night store, liquor store \\
3 & Uncultivated greenery \\
4 & Neglected buildings (neglected facades, woodwork etc.) \\
5 & Vacant properties, ruins \\
6 & Trails \\
7 & Garbage enclosures \\
8 & Narrow passageways between buildings \\
9 & Proximity of a cemetery \\
10 & Unguarded parking lots \\
11 & Protruding stairwells without intercoms, gates and yards in tenements \\
12 & Slopes \\
13 & Other (underpasses, bridges etc.) \\
14 & Forest, park \\
15 & Graffiti \\
16 & Bus stops \\
17 & Illegal waste dumps \\
\hline
\end{tabular}

\section{Evaluation of urbanized geospatial features in the context of safety}

Many qualitative features can be measured quantitatively in many ways, by using existing statistics or by conducting appropriate studies [10]. The questionnaire method was used in this paper to determine the importance of specific spatial features for safety.

The questionnaire survey was conducted in a group of third-year, full-time students (74 questionnaires) in the field of Land Management of the Faculty of Geodesy and Land Management at the University of Warmia and Mazury in Olsztyn. The respondents evaluated individual features with a negative effect on spatial safety by direct comparison. The evaluation was made in rows for the feature specified in the first column of the table, with instructions that an arrow should be directed towards the feature which contributes to danger in urban space more strongly than the other feature. Additionally, if the respondent decided that the features contributed to spatial danger with the same force, for both evaluated features, the value 0 was written in this field (Table 2).

Table 2. Evaluation criteria

\begin{tabular}{ll}
\hline Direction & Number of points \\
\hline$\uparrow$ & 0 \\
$\leftarrow$ & 2 \\
0 & 1 \\
\hline
\end{tabular}

The questionnaire data were handled using the point criteria adopted in Table 2 . The results were then standardized by quotient transformation relative to the reference point, where the maximum value, obtained from adding up individual columns, was adopted as the reference point and the arithmetic mean of all questionnaires was then computed (Table 3).

Table 3. Survey results

\begin{tabular}{llllllllllllllllll}
\hline Feature number & 1 & 2 & 3 & 4 & 5 & 6 & 7 & 8 & 9 & 10 & 11 & 12 & 13 & 14 & 15 & 16 & 17 \\
\hline $\begin{array}{l}\text { Survey results } \\
\%\end{array}$ & 8 & 7 & 7 & 5 & 9 & 7 & 5 & 7 & 6 & 5 & 5 & 3 & 8 & 8 & 2 & 4 & 4 \\
\hline
\end{tabular}


The results allowed a set of safe space valuation features to be isolated. The percentage share for the presence of a given spatial feature is inversely proportional to safety. The features most contributing to a spatial danger are: unlit streets, vacant properties, ruins, other (underpasses, bridges, etc.) and a forest or park (these features obtained from 8-9\%). The second group of features whose presence in space generates a danger are: clubs, pubs, all-night store, liquor stores, uncultivated greenery, trails, narrow passageways between buildings and the proximity of a cemetery (these features obtained from 6$7 \%$ ). The features least contributing to spatial danger according to the respondents are slopes and graffiti.

\section{Risk map}

An evaluation of spatial elements was undertaken to isolate the urbanized space areas generating danger. For standardization and the possibility of result interpretation, the analysis was performed for estates in the eastern part of the city of Olsztyn. Geoinformation was evaluated for each estate, taking into account the presence intensity of individual features in the estates.

The safety risk map was generated after a comprehensive evaluation of all elements. Visualization was performed by a point valuation based on 3 valuation classes (Fig. 1).

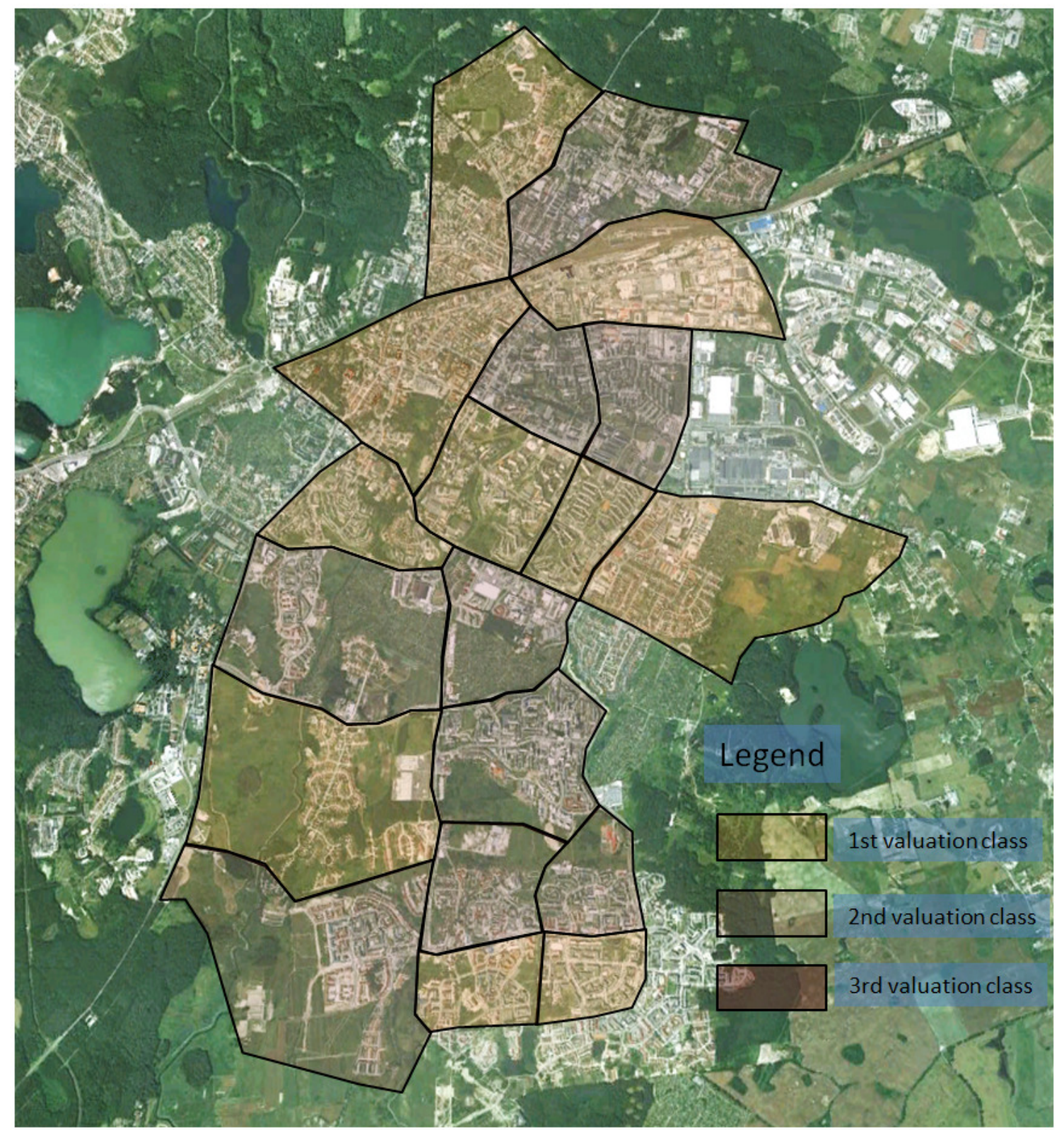

Fig. 1. Safety risk map for a fragment of the city of Olsztyn

Risks understood as dangerous spaces are estates in the 1st valuation class, with point ranges from 100 to 67 . In estates with point ranges from 66 to 33 (2nd valuation class), spatial danger is moderate and in the other evaluated estates it is low, with point ranges from 33 to 0 (3rd valuation class) 


\section{Conclusions}

Attempts can be made to define what affects a spatial evaluation, but it is hard to unequivocally determine the preferences of all potential users. Despite individual differences in the perception of space, the human tendency to evaluate one's immediate environment helps to determine which places will be more or less safe.

The organization of the space surrounding us affects our way of perceiving this space. A lack of connection between a spatial feature and safety causes discomfort in a spatial use. The user ceases to feel safe in a particular urban environment and his or her evaluation is negative.

When evaluating urban safety, it should also be examined whether land features affect safety. The state of development are the urban environment features which are also evaluated in the context of space safety. Designers' visions are driven by economics and local politics, but they should also take into account the expectations of the residents, who wish to live in a safe environment. Safe spaces should be shaped by eliminating features contributing to spatial danger.

\section{References}

[1] Bańka, A. 2002. Social environmental psychology. Scholar Scientific Publishers, Warszawa.

[2] Lewicka, M. 1999. http://www.psych.uw.edu.pl/katalog/kursy zimowe/140-1.html.UW (University of Warsaw), Faculty of Psychology.

[3] Bartnicka, M. 1989. Imagery of Warsaw's urban space. (Perception geography study) Geographical Documentation, Volume 2, Wrocław, Warszawa, Kraków, Gdańsk, Łódź.

[4] Libura, H. 1988. Geographical imagery studies based on the example of Sanok residents. Outline of aesthetics, PWN, Warszawa.

[5] Cymerman, R.; Hopfer, A.; Koreleski, K.; Magiera-Braś, G. 1988. Application of an impression curve method for evaluation of the landscape of rural areas. ZN 18, ART. Olsztyn.

[6] Bajerowski, T. 1991. Evaluation, protection and shaping of the rural landscape, as an element of programming agricultural land management work. PhD dissertation, Olsztyn.

[7] Więckowicz, Z. 1996. Needs and possibilities for multifunctional development of the Trzebnica commune. ZN 296, AR, Wrocław.

[8] Zedler, J. 1999. The participants association as the basic administrative unit for rural development in Bavaria, ZN 68, AR, Kraków.

[9] Gerus-Gościewska, M. 2000. Evaluation of the neighborhood of planning functions taking into account spatial perception. UWM Olsztyn.

[10]Jeleński, T.; Kosiński, W. 2009. How to Turn a Place Around: A Handbookfor Creating Successful Public Spaces, Project for Public Spaces. Inc., Polish edition - Partnership for the Environment Foundation, Printed by: BROS s.c.

[11] Spatial Planning and Land Development Act of 27 March 2003, Dz.U. 2003 Nr 80 poz. 717. 